\title{
Antecedents of work-family conflict among Egyptian civil workers
}

\author{
E. S. Eshak ${ }^{1,2}$ (1) A. S. Elkhateeb ${ }^{1}$ - O. K. Abdellatif ${ }^{1}$ - E. E. Hassan ${ }^{1}$ - E. S. Mohamed ${ }^{1} \cdot$ E. R. Ghazawy ${ }^{1}$ - S. A. Emam ${ }^{1} \cdot$ \\ E. M. Mahfouz ${ }^{1}$
}

Received: 10 May 2021 / Accepted: 28 July 2021

(C) The Author(s), under exclusive licence to Springer-Verlag GmbH Germany, part of Springer Nature 2021

\begin{abstract}
Aim Previous studies have suggested variable levels of associations between work-family conflict (W_F_C) and its antecedents in different populations. We aimed to assess the antecedents of this conflict and its two types; work-to-family (WFC) and familyto-work (FWC) among Egyptian civil workers.

Subjects and methods In a convenience sample of 3134 Egyptian civil workers, we assessed the W_F_C using the National Study of Midlife Development in the US and attributed it, by logistic and linear regression analyses, to several sociodemographic, work/family situational, behavioral, and health-related variables which were collected by a questionnaire survey between October 2019 and January 2020.

Results W_F_C was prevalent in $56 \%$ of the sample ( $51 \%$ for WFC and $62 \%$ for FWC). The work and family situational factors were the most significant antecedents of the W_F_C and its two types; partial $R^{2}$ was 0.71 . Both the health-related and behavioral clusters of antecedents were also predictors of $\mathrm{W}_{-} \mathrm{F}_{-} \mathrm{C}$, while the sociodemographic antecedents contributed minimally to the FWC. The multivariable odds ratios (95\% CIs) for high W_F_C in those with high vs low work demands, job control, social support at work, and family were 4.11 (2.89-7.03), $0.0(0.66-0.90), 0.86(0.62-0.98)$, and 0.74 (0.59-0.94), respectively.

Conclusions Work and family situational factors were the most significant antecedents of the levels of W_F_C in Egyptian civil workers. The Egyptian authorities could reduce the civil workers' W_F_C by improving the work environment, finding ways to relieve the workload demands, and helping the civil workers to have more job control and social support.
\end{abstract}

Keywords Work-family conflict · Antecedents · Civil workers · Egypt

\section{Introduction}

The most commonly known definition of work-family conflict (W_F_C) is "a form of inter-role conflict in which the role pressures from the work and family domains are mutually incompatible in some respect" (Greenhaus and Beutell 1985). Thus, the basic understanding of the definition implies imbalances in the individual's degrees of responding to the requirements (time, strain, and expectations) and the perception of resources (financial, instrumental, and emotional

E. S. Eshak

ehab@pbhel.med.osaka-u.ac.jp

1 Public Health Department, Faculty of Medicine, Minia University, Main Road, El-Minia, Shalabyland 61511, Egypt

2 Public Health, Department of Social Medicine, Graduate School of Medicine, Osaka University, Osaka, Japan support) for both work and family. When these imbalances are in favor of work at the expense of the family, the direction of conflict is work-to-family conflict (WFC); whereas, when the imbalances are in favor of family at the expense of the work, the direction of conflict is family-to-work conflict (FWC) (Michel et al. 2011). Since the publications of Byron's review on the measures of work-nonwork including the work-life conflict in 2005 (Byron 2005), the research on W_F_C has expanded greatly.

In Egypt, with the enforcement of women-empowering policies such as providing more chances in the labor market (Alkitkat 2018), and the currently ongoing economic reform (Eshak 2019a), findings from the scarce available, small sample-sized studies showed a high prevalence of W_F_C that was associated with adverse physical and mental health outcomes among Egyptian community dwellers (Eshak et al. 2018; Eshak 2019b). Thus, to curb the conflict of this burden, it is necessary to study its causes and antecedents among larger samples of Egyptian civil workers. 
Based on the earlier research findings, the work boundaries are usually stricter than the family boundaries, leading to WFC being more prevalent than FWC (Michel et al. 2011; Eshak et al. 2018). The current study aims to explore the antecedents of W F C and to examine if the antecedents of WFC will differ from those of FWC among Egyptian civil workers.

\section{Methods}

\section{Study design and population}

Just before the awareness and spread of the COVID-19 pandemic, in January 2020, the Public Health Department, Faculty of Medicine, Minia University, with the aid of the Japan Society for the Promotion of Science (JSPS), through the basic research C general fund no. 19 K10621 (KAKEN Researcher 2021, May 8) had finished the data collection step for a cross-sectional study among Egyptian civil workers in a central Egyptian governorate (Minia governorate) to compare the effects of W_F_C on the cardiometabolic profile and mental health of Egyptian and Japanese civil workers. The current research paper is based on the data collected from 3143 Egyptian civil workers recruited through a convenience sample between October 2019 and January 2020 from different institutions (local and central municipalities, hospitals, schools, etc.) all over Minia governorate. The inclusion criteria of the recruited civil workers were: 1 - being a fulltime civil worker, 2 - working under the authority of the governor of Minia governorate, 3 - willing to participate in the study.

After getting the ethical approval of Minia University, Faculty of Medicine ethical review board for the research project (approval no 194:4/2019), the data collection team (20 trained members) visited the randomly selected institutions at the beginning of a certain working day (after contacting the authorities there in advance), and the manager of each institution provided the team with a room in which they described the nature and purpose of the study to the civil workers, distributed a self-administered questionnaire to those who signed the informed consent asking them to fill in the questionnaire before the end of the working day, provided guidance whenever necessary all through the working day, and conducted anthropometric and blood pressure measurements to those who returned the questionnaire.

Of 5000 questionnaires distributed, 3814 willing to participate civil workers returned the questionnaire, and 3143 questionnaires had been completed without considerable missing items. The questionnaire inquired about the demographic, social, work, and family characteristics, health-related items, and lifestyle of the participants.

\section{Work-family conflict}

The National Study of Midlife Development in the United States (Grzywacz and Marks 2000) validated a four-point Likert scale $(0=$ never, $1=$ to some extent, $2=$ often $3=$ always) response to eight items assessing W_F_C. This scale was used in previous studies conducted on the Egyptian population and showed very good internal consistencies as measured by the Cronbach's alpha test (Eshak et al. 2018; Eshak 2019a). The following four items were used to assess the FWC: "Some domestic problems reduce the amount of time you need for your work", "Home worries or problems can distract you from work", "Housework can prevent you from getting the sleep you need to get your job done", and "Responsibilities at home reduce the time to relax as yourself". The other four items were used to assess the WFC: "Because of my work, I spend less time with my family", "I am annoyed at home because of problems at work", "I often leave home on business trips", and "At home, I think I cannot do anything that requires my attention because my work consumes my energy".

According to the median value of the sum score of the FWC items, we categorized the participants into those with low ( $<$ median value) and high ( $\geq$ median value) FWC, and we did similarly for the WFC score. Also, we summed the scores of the eight items and dichotomized the total score into low ( $<$ median value) and high ( $\geq$ median value) total F_W_C categories.

\section{The antecedents}

We hypothesized that the questionnaire's variables which could determine the level of W_F_C can be clustered into the following four main groups: -.

A- Sociodemographic antecedents [age, sex, residence (urban/rural), education (less than high school, high school, or university and above), marital status (single, married, divorced, or widowed), living arrangement (living alone, living with a spouse only, or living with a multigeneration family), occupation (clerk, professional, or worker/technician), and the monthly household income ( $<$ or $\geq 5000$ EGP).

B- Situational antecedents representing the situation at the level of both work and family. The work situational antecedents included the following:

- Job demands, which were measured by three items, each assessed by a single (yes/no) question: role overload "Do you feel like you have too much work allotted to you?", role ambiguity "Do you know what is expected of you at work?", and role conflict "Do 
you frequently have to deal with conflicts in the workplace?"

- Job control, which was measured by two items, each assessed by a single (yes/no) question: skill discretion “Are you allowed to solve work's urgent/ unforeseen problems on your own?" and decision authority "Are you involved /consulted in the decisions taken in your workplace?"

- Social support at the workplace, which was measured by three items, each assessed by a single (high/low) self-assessment: institution support, supervisor support, and coworkers support.

The family situational antecedents included the following four items: working spouse (yes/no), having children below 14 years old (yes/no), giving financial support to other family members (yes/no), and the level of social support perceived from the family (high/low).

C- Behavioral antecedents representing the lifestyle and habitual behaviors of the participants, which included the following:

- Physical activity, which was measured in metabolic equivalent of task (METs) units before we dichotomized it, according to the median value, into physically more active vs physically less active.

- Smoking habit of both cigarettes and shisha, which was categorized as never, former, and current smokers.

- Sleep disorders which were measured by the Jenkins Sleep Questionnaire (Jenkins et al. 1988) and the Fourth Edition of Diagnostic and Statistical Manual of Mental Disorder (American Psychiatric Association 2000).

D- Health-related antecedents representing the subjective and objective assessments of the participants' physical and mental health through the following three items:

- Self-reported health: each participant ranked his current health status as poor, not good, good, very good, or excellent before we dichotomized it into poor vs good self-reported health.

- Medical history of chronic diseases: yes or no answer for the medical history of hypertension, diabetes, hyperlipidemia, stroke, ischemic heart disease, and/or cancer.

- The score of the Center for Epidemiologic StudiesDepression (CES-D) 20-items scale (Radloff 1977) which we categorized as poor ( $\geq 16$ points) vs good (<16 points).

\section{Statistical analysis}

The characteristics of the total recruited sample of Egyptian civil workers and the levels of the hypothesized W_F_C antecedents among these civil workers were represented as mean (SD) or proportions. The Student's $t$-test and the $\chi^{2}$ test were used to detect statistically significant differences in these variables among civil workers with low vs high levels of total W_F_C, WFC, and FWC. The multivariate logistic regression models were used to compute the odds ratios (ORs) and $95 \%$ confidence intervals (CIs) of the likelihood to have high levels of W_F_C, WFC, and FWC by having the above-mentioned antecedents.

Within each cluster of the hypothesized antecedents, the first multivariable model tested the associations between each item in this cluster and the W_F_C outcomes, after adjusting for the other items in the same cluster only. Meanwhile, the second (final) multivariate model included all the variables of the four hypothesized clusters of antecedents simultaneously.

Additionally, each of the eight, seven, three, and three items constituting the sociodemographic, situational, behavioral, and health-related clusters of antecedents was dichotomized into favorable $=0$ and unfavorable $=1$. The unfavorable criteria for the sociodemographic cluster of antecedents were young age, males, urban residence, highly educated, not single, not living alone, professional work, and a low household income. For the situational cluster of antecedents, the unfavorable criteria were high job demands, low job control, low social support at work, no working spouse, giving financial aid to other family members, living with children aged under 14 years old, and perceived low social support from family. Being physically less active, being a current smoker of cigarettes and/or shisha, and having sleep disorders were the unfavorable criteria for the behavioral cluster of antecedents. For the health-related cluster of antecedents, the unfavorable criteria were self-reporting of poor health, having a medical history of chronic diseases, and/or having depressive symptoms. The total scores of the above-mentioned clusters of antecedents ranged from 0 to 8,0 to 7,0 to 3 , and 0 to 3 respectively, and higher scores reflected unfavorable characteristics.

We tested the crude and mutually-adjusted association of dichotomized levels of W_F_C, WFC, and FWC (high versus low) with the total score of each cluster of antecedents using logistic regression analysis. We also tested the linear associations of the continuous scores total W_F_C, WFC, and FWC with the continuous scores of these clusters of antecedents using stepwise linear regression analysis. All statistical analyses were conducted using the SAS, version 9.4 software (SAS Institute Inc., Cary, NC, USA), and two-tailed $p$ values of $<0.05$ were considered to show statistical significance. 


\section{Results}

The mean (SD) of age, METs, and CES-D, W_F_C, WFC, and FWC scores of the total 3143 recruited Egyptian civil workers were $40.8 \pm 10.6$ years, $31.8 \pm 10.2$ units, and $21.9 \pm 9.4,15.0 \pm 4.5,8.0 \pm 2.9$, and $7.0 \pm 2.4$ points respectively. The proportions of males, highly-educated, professionals, currently married, and living alone participants were $48.9 \%, 61.8 \%, 57.2 \%, 83.4 \%$, and $1.4 \%$ respectively.

Younger age and having any of the following - high job demands, low job control, low social support at work or family, non-working spouse, children under 14 years old, financial responsibilities to other family members, sleep disorders, poor self-rated health, and higher scores of the CES-D scale - were more common in Egyptian civil workers who ranked high in both WFC and FWC levels. The proportions of males and currently unmarried participants were higher in the group of high vs low WFC, while the higher proportions of females and currently married participants were higher in the group of high vs low FWC. The highest education level was more common in the high conflict groups, especially those with high WFC compared to those with high FWC (Table 1).

Table 2 shows the multivariable associations between the hypothesized antecedents and the dichotomized levels of W_F_C, WFC, and FWC.

\section{A-sociodemographic antecedents}

In the model containing the eight sociodemographic variables, only age, sex, marital status, and education were significant antecedents of both WFC and FWC. However, in the fully adjusted model including all the hypothesized antecedents, only younger age remained a significant antecedent of having high WFC; the multivariable OR $(95 \%$ CI) was 0.82 (0.750.90 ) for a 5 -year increment in age. Female gender and being single were inversely associated with high W_F_C and FWC levels; the multivariable ORs (95\% CIs) were $0.81(0.68-$ $0.96)$ and $0.61(0.41-0.90)$ for W_F_C and $0.68(0.53-$ 0.76 ), and $0.31(0.21-0.47)$ for FWC (Table 2). The total sociodemographic score anticipated a high total W_F_C; however, after adding the scores of the other three clusters of antecedents into the model, the association disappeared.

\section{B-situational antecedents}

All the work situation variables were significant antecedents of both WFC and FWC; the multivariable ORs (95\% CIs) of having high levels of WFC and FWC were $4.63(2.96-7.25)$ and $2.86(2.00-4.08)$ for high job demands, $0.66(0.50-0.78)$ and $72(0.49-0.85)$ for high job control, and $0.70(0.59-0.91)$ and $0.80(0.50$ 0.98 ) for high social support at work. Having a working spouse was associated with lower odds of having WFC [multivariate $\mathrm{OR}=0.72(0.55-0.91)]$ but higher odds of having FWC [multivariate OR $=1.41(1.06-1.86)$ ]. Giving financial aids to other family members was associated with an OR of $3.31(2.42-4.50)$ of having high WFC, while living with children aged less than 14 years was associated with higher odds of having high FWC $[\mathrm{OR}=1.29(1.07-1.82)]$. Perceiving a high level of social support from the family was a significant antecedent of a low level of all types of conflict. The total situational score was the most significant predictor of both types of conflict and the overall W_F_C, even after adjusting for the total scores of the other three clusters of antecedents.

\section{C-behavioral antecedents}

Having sleep disorders was the only significant behavioral antecedent of both WFC and FWC; the multivariable ORs (95\% CIs) were 2.17 (1.80-2.72) and 1.89 (1.37-2.20). Neither physical activity nor smoking habit were associated with W_F_C. The total behavioral score anticipated high W_F_C; however, after adding the total scores of the other three clusters into the model, the associations were greatly attenuated.

\section{D-health-related antecedents}

The self-report of poor health was associated with increased, but insignificant, odds of having a high WFC [OR was 1.56 (0.97-2.52)], while a 10-points increment in the CES-D scale of depressive symptoms was a significant antecedent of WFC and FWC [ORs (95\% CIs) were 1.31 (1.17-2.02) and 2.00 (1.74-2.29)]. The total health status score was a significant predictor of both types of conflict and the overall W_F_C, even after adjusting for the total scores of the other three clusters of antecedents.

Table 3 shows the mutually-adjusted linear regression analyses between the continuous scores of W_F_C, WFC, and FWC, with the total scores for antecedents. The WFC and the FWC scores were best predicted by the situational, sociodemographic, and health-related clusters of antecedents; $R^{2}=0.56$ for WFC and 0.26 for FWC. The total W_F_C score was best predicted by a model containing the situational, behavioral, and health-related clusters of antecedents; $R^{2}=$ 0.72 . The highest partial correlation coefficient - which is a measure of the strength of the linear relationship between the score of each cluster of antecedents and the scores of W F C, WFC, and FWC after correlations with the scores of the other three clusters of antecedents are removed - was that with the situational cluster of antecedents; partial $R^{2}$ was 0.7093 for total W_F_C, 0.5588 for WFC, and 0.2468 for FWC. 


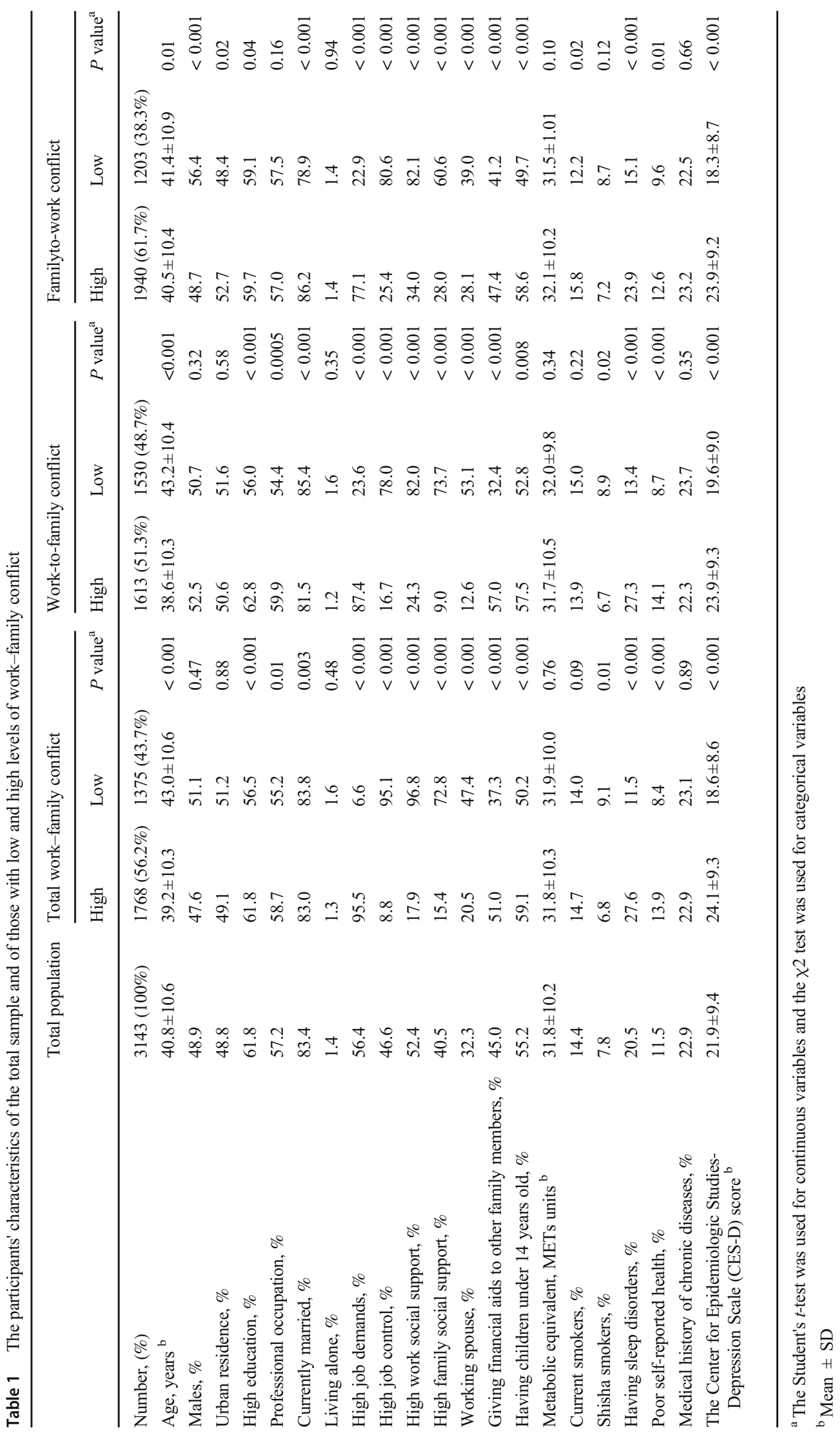




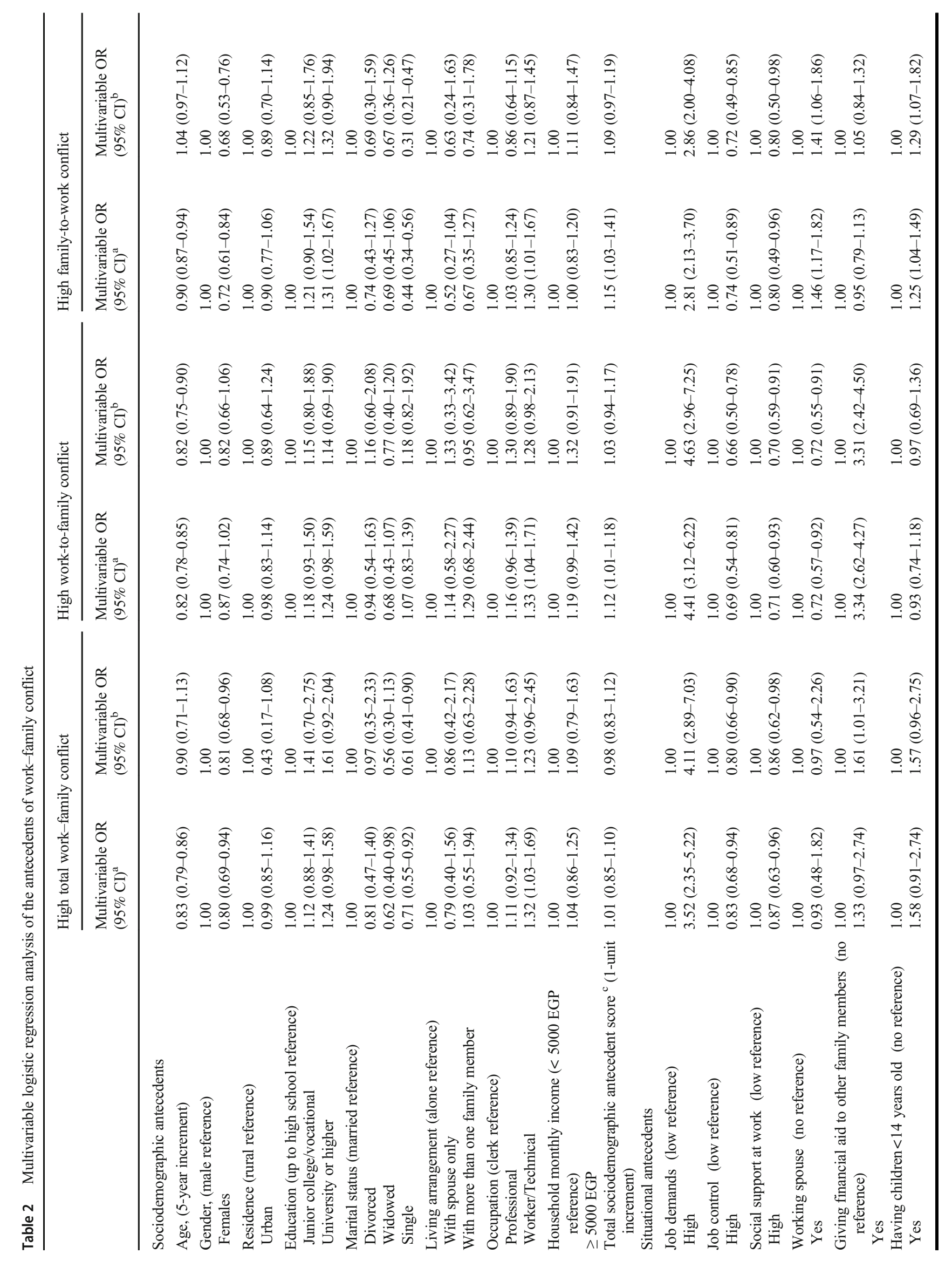




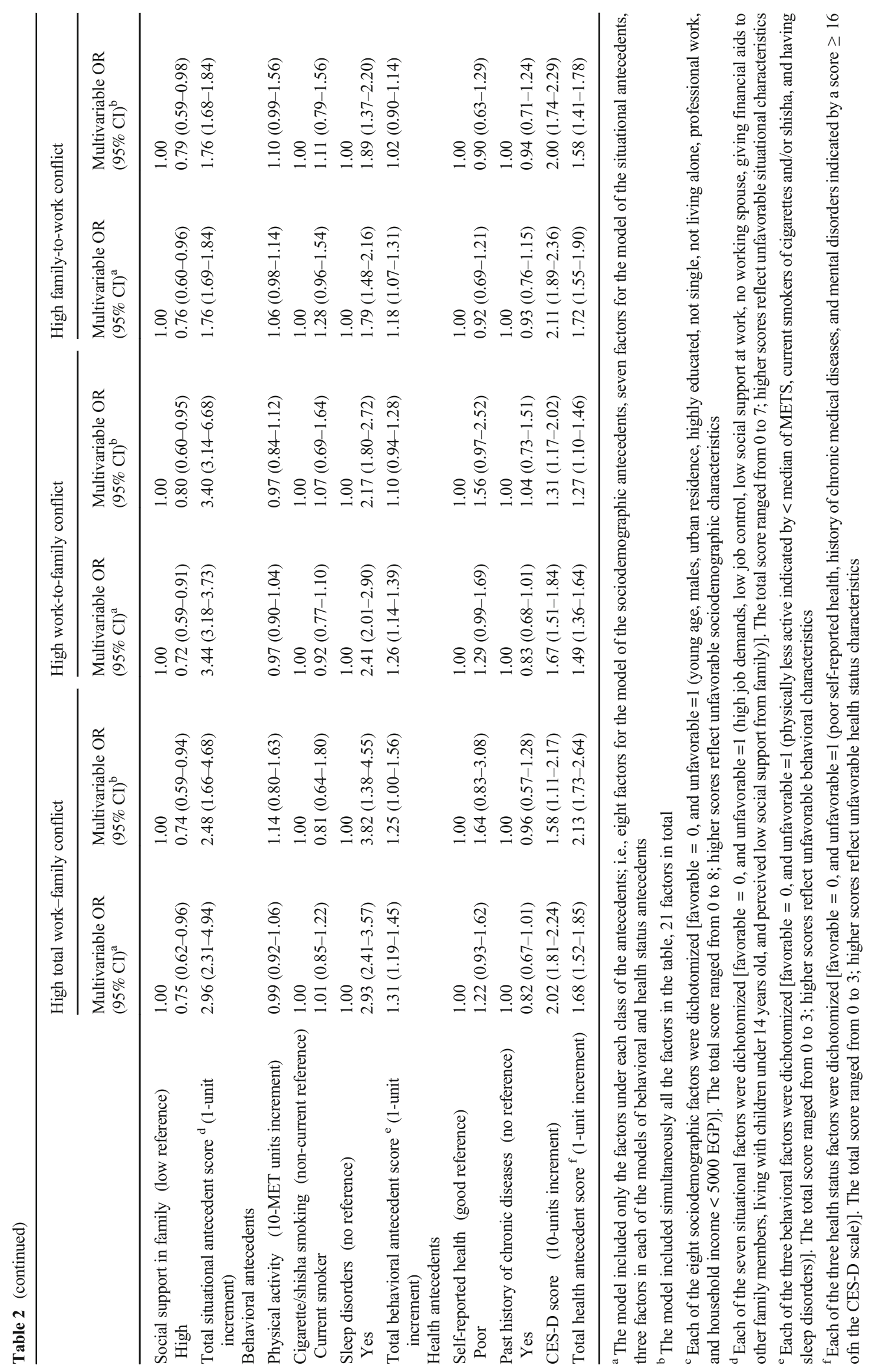


Table 3 Linear stepwise regression analysis a of work-family score and different antecedents scores

\begin{tabular}{|c|c|c|c|c|c|c|c|c|c|c|c|c|}
\hline & \multicolumn{4}{|c|}{ Total work-family conflict score } & \multicolumn{4}{|c|}{ Work-to-family conflict score } & \multicolumn{4}{|c|}{ Family-to-work conflict score } \\
\hline & Partial $R^{2}$ & $\beta$ & $\begin{array}{l}\mathrm{F} \text { - } \\
\text { value }\end{array}$ & $P$ value & Partial $R^{2}$ & $\beta$ & $\begin{array}{l}\mathrm{F}- \\
\text { value }\end{array}$ & $P$ value & Partial $R^{2}$ & $\beta$ & $\begin{array}{l}\mathrm{F}- \\
\text { value }\end{array}$ & $P$ value \\
\hline Sociodemographic score & & & & & 0.0005 & 0.01 & 3.4 & 0.066 & 0.0023 & 0.02 & 9.8 & 0.002 \\
\hline Situational score & 0.7093 & 0.19 & 7624.2 & $<0.001$ & 0.5588 & 0.17 & 3957.3 & $<0.001$ & 0.2468 & 0.11 & 1023.9 & $<0.001$ \\
\hline Behavioral score & 0.0057 & 0.01 & 62.4 & $<0.001$ & & & & & & & & \\
\hline Health status score & 0.0004 & 0.05 & 4.2 & 0.04 & 0.0025 & 0.03 & 18.1 & $<0.001$ & 0.0148 & 0.08 & 62.4 & $<0.001$ \\
\hline
\end{tabular}

${ }^{a} R^{2}$ values were $0.72,0.56$, and 0.26 for the final models predicting total work-family conflict score, work-to-family conflict score, and family-to-work conflict score respectively

\section{Discussion}

In this cross-sectional study, W_F_C was prevalent in $56 \%$ of the recruited 3143 Egyptian civil workers. High levels of WFC and FWC were found in $51 \%$ and $62 \%$ of the participants respectively. The work and family situational factors were the most significant antecedents of the W_F_C and its two types. Both the health-related and behavioral clusters of antecedents were also predictors of W_F_C, while the sociodemographic cluster of antecedents was contributing to a minor degree to the conflict, mainly for FWC.

The findings that sociodemographic factors played a limited antecedent role in the W_F_C could be justified in light of the conclusion of the meta-analysis conducted by Byron 2005 that the most important individual antecedents of W_F_C were the personality traits and trait emotional intelligence rather than the demographic characteristics. Some personal traits such as conscientiousness and agreeableness were seen as helpful in dealing with stress and strain, while characteristics such as neuroticism would exacerbate W_F_C (Rantanen et al. 2005). One important finding was that the female gender was an antecedent of low levels of W_F_C, especially with regard to FWC in our study. The previous research produced extremely contradictory findings of whether there were significant mean W_F_C differences between men and women (Voydanoff 2002). Some studies suggested that women rather than men experienced more WFC (Fu and Shaffer 2001), while other studies reported the opposite (Hammer et al. 2002). For the risk of FWC, some previous research indicated that women experienced greater levels of FWC ( $\mathrm{Fu}$ and Shaffer 2001; Kobayashi et al. 2017), while other studies reported no gender difference in the FWC levels (McElwain et al. 2005). The exact mechanism by which the female gender anticipated low FWC in our study is unclear; however, McElwain et al. 2005 suggested that among full-time employees (such as in our case of Egyptian civil workers), no gender-role orientation differences could be detected if the couples were dual-earners and only those who were high in instrumentality expressed lower levels of FWC, regardless of gender (McElwain et al. 2004). In our study, the percentages of being married to a working spouse, i.e., dual-earner families, were $15 \%$ among men and $52 \%$ among women; thus, considering this together with the speculation that Egyptian working women might be higher in instrumentality than men, the low FWC in women could be plausible. Moreover, those who were single in our study were, logically, low in FWC, and the proportion of single females $(15 \%)$ was higher than single males $(8 \%)$.

Our findings that the work and family situational factors were highly significant antecedents of W_F_C with its two types WFC and FWC match the previous studies' findings. High job demands, low job control, and low social support at work were associated with high levels of W_F_C in Japan (Kato and Yamazaki 2009), the US (Janssen et al. 2004), Europe (Kinnunen and Mauno 1998), and in other developing countries as well (Michel et al. 2011; Byron 2005). Several theories were proposed to link situational factors at both work and in the family with W_F_C. The role theory and resource drain theory hypothesize that with the limited time, energy, and ability to give care an individual has, the characteristics of the work (job demands, control, support, etc..), and family (working spouse, number of young children, and social support, etc..) impact the expectations for work/family roles and role performance in an incompatible direction (conflict theory) (Michel et al. 2011; Byron 2005). An interesting finding of our study was that giving financial aid to other family members was associated with high levels of WFC, and, to the contrary, being married to a working spouse was associated with lower levels of WFC. From an economic point of view, the increased financial demands required by the family could have forced the participants to put in more time and energy to work at the expense of the family (Eshak et al. 2018); while having a working spouse could have neutralized this financial burden. However, it seems that neutralizing the financial burden was not without a price, because those who were married to working spouses (dual-earner families) were shown to face high levels of FWC. When both partners are simultaneously out at work, they may, unconsciously, depend on each other for family care, leading to high FWC levels, especially when there are young children in the family. 
The level of social support both at work and in the family was a significant antecedent of W_F_C, which matches the findings among other populations (Selvarajan et al. 2013; Kossek et al. 2011). Social support can protect the individual's well-being under adverse circumstances via a direct mitigating effect on stressors and/or by buffering the stressors and strains (French et al. 2018).

Among the studied behavioral cluster of antecedents, sleep disorders were significantly associated with W_F_C. Previous studies showed similar associations in both Egyptians (Eshak 2019a) and other populations (Sekine et al. 2006). The time for sleep is a common source to borrow from if one domain (work or family) infringed on the time required by the other domain.

The psychological health of the studied civil workers, represented by the score of the CES-D scale, was the significant variable among the health-related cluster of antecedents. This was in match with the result of a previous study among community dwellers in Egypt (Eshak 2019b), where the multivariable odds of having mental health disorders were 2.26 (1.184.34) and 1.37 (0.78-2.41) for community dwellers with high WFC and FWC respectively. Similar results were reported in other populations (Wang 2005; Huang et al. 2004).

This is the first large-scale study to describe the associations between W_F_C and several clusters of its hypothesized antecedents in Egyptian civil workers. However, limitations that should be mentioned include its cross-sectional design with its inability to catch temporal associations. Indeed, many of the hypothesized antecedents could be seen, in the point of view of many researchers, as moderators, mediators, or outcomes, rather than antecedents of the W_F_C (Korabik et al. 2008); thus, future longitudinal studies are recommended. We also should discuss the drawbacks of convenience sampling. As we recruited a non-probability sample, thus the results cannot be considered representative of the whole target population. For example, the proportion of female respondents to the questionnaire in our sample was higher than that of males, which should not be interpreted as higher proportions of female civil workers than male ones in Egypt. Also, there was an overrepresentation of highly educated civil workers (university level or above) in our sample. We cannot guarantee how much the differences were in the levels of W_F_C and/or its studied antecedents between civil workers who responded and those who did not respond to the questionnaire. Another limitation is the self-reported data; however, we collected the data related to the W_F_C and its antecedents via complex scoring algorithms or selected questions of previously validated tools. Last, despite being a very good tool to capture the antecedents of total W_F_C $\left(R^{2}=0.72\right)$ and WFC and $\left(R^{2}=0.56\right)$, our questionnaire and the hypothesized clusters of antecedents were relatively fair in terms of predicting the levels of FWC $\left(R^{2}=0.26\right)$.
In conclusion, work and family situational factors were the most significant antecedents of the levels of W_F_C in Egyptian civil workers. Both the behavioral and healthrelated antecedents contributed fairly to the level of W_F_C, while the sociodemographic cluster of antecedents had the lowest contribution to the level of W_F_C experienced by the studied Egyptian civil workers. The implications of these findings could help the authorities in Egypt to improve the organizational productivity and the familial context of society. Alleviating the effects of W_F_C could be done through improving the work environment, finding ways to relieve the workload demands, and helping the civil workers to have more job control and social support.

Acknowledgments We thank the Japan Society for the Promotion of Science (JSPS) for providing the research grant of this research. Our deep gratitude to our colleagues from Osaka University Center of Medical Data Science, Advanced Clinical Epidemiology Investigator's Research Project for providing their insight and expertise for our research. We appreciate the efforts of all the staff members of the Public Health Department, Faculty of Medicine, Minia University who helped in managing the data collection, entry, and clearance, specifically Drs. Maggi M. Ayad, Shaimaa M Ahmed, Nehal R Raouf, Amany M Reda, Chrestina M Fekry, Shaza F Mohamed, Sara M Sayed, Asmaa M Taha, Yasmine N Gaballah, Hager A Zaki.

Authors' contribution ESE designed the research, analyzed the data, and drafted the manuscript, ASE, OKA, EIH, ESM, ERG, SAE, and EMM supervised data collection and provided critical review of the research article.

Sources of funding This study was supported by the Japan Society for Promotion of Science (JSPS) fund, grant-in-aid for basic research C general no 19 K10621 (2019-2022).

Availability of data and material Available upon justified request.

Code availability Not applicable.

\section{Declarations}

Conflict of interest The authors declare no conflict of interest.

Ethics approval All procedures performed in this study were in accordance with the ethical standards of Minia University, Faculty of Medicine research committee and with the 1964 Helsinki Declaration and its later amendments or comparable ethical standards.

Consent to participate Informed consent was obtained from all individual participants included in the study.

Consent for publication Not applicable.

\section{References}

Alkitkat H (2018) Egyptian female labor force participation and the future of economic empowerment. Springer briefs in political science. Springer, Cham. https://doi.org/10.1007/978-3-319-59644-0

American Psychiatric Association (2000) Diagnostic and statistical manual of mental disorders. 4th Ed., text revision. American Psychiatric Association, Washington DC 
Byron K (2005) A meta-analytic review of work-family conflict and its antecedents. J Vocat Behav 67:169-198

Eshak ES (2019a) Work-to-family conflict rather than family-to-work conflict is more strongly associated with sleep disorders in Upper Egypt. Ind Health 57(3):351-358. https://doi.org/10.2486/indhealth. 2018-0091

Eshak ES (2019b) Mental health disorders and their relationship with work-family conflict in Upper Egypt. J Fam Econ Iss 40(4):623632. https://doi.org/10.1007/s10834-019-09633-3

Eshak ES, Kamal NN, Sedhom AE, Kamal NN (2018) Work-family conflict and self-rated health among dwellers in Minia, Egypt: financial strain vs social support. Public Health 157:69-76. https:// doi.org/10.1016/j.puhe.2018.01.016

French KA, Dumani S, Allen TD, Shockley KM (2018) A meta-analysis of work-family conflict and social support. Psychol Bull 144(3): 284-314. https://doi.org/10.1037/bul0000120

Fu CK, Shaffer MA (2001) The tug of work and family: direct and indirect domain-specific determinants of work-family conflict. Pers Rev 30(5):502-522

Greenhaus J, Beutell N (1985) Sources of conflict between work and family roles. Academy Management Review 10(1):76-88

Grzywacz JG, Marks NF (2000) Reconceptualizing the work-family interface: an ecological perspective on the correlates of positive and negative spillover between work and family. J Occup Health Psychol 5:111-126

Hammer LB, Colton CL, Caubet SL, Brockwood KJ (2002) The unbalanced life: work and family conflict. In: Thomas J, Herson M (eds) Handbook of mental health in the workplace. Sage, Thousand Oaks

Huang YH, Hammer LB, Neal MB, Perrin NA (2004) The relationship between work-to-family conflict and family-to-work conflict: a longitudinal study. J Fam Econ Iss 25:79-100

Janssen PMP, Peeters CWM, de Jonge J, Houkes I, ERG T (2004) Specific relationships between job demands, job resources and psychological outcomes and the mediating role of negative work-home interference. J Vocat Behav 65:411-429

Jenkins CD, Stanton BA, Niemcryk SJ, Rose RM (1988) A scale for the estimation of sleep problems in clinical research. J Clin Epidemiol 41:313-321

KAKEN Researcher (2021) Grants-in-Aid for Scientific Research Database. Available at: https://nrid.nii.ac.jp/en/nrid/100004 0835021/

Kato M, Yamazaki Y (2009) An examination of factors related to workto-family conflict among employed men and women in Japan. J Occup Health 51(4):303-313. https://doi.org/10.1539/joh.18099

Kinnunen U, Mauno S (1998) Antecedents and outcomes of work family conflict among employed women and men in Finland. Hum Relat $51: 157-177$
Kobayashi T, Honjo K, Eshak ES, Iso H, Sawada N, Tsugane S, Japan Public Health Center-based Prospective Study for the Next Generation (JPHC-NEXT) Study Group (2017) Work-family conflict and self-rated health among Japanese workers: how household income modifies associations. PLoS One 12(2):e0169903. doi: https://doi.org/10.1371/journal.pone.0169903

Korabik K, Lero D, Denise Whitehead D (2008) Handbook of workfamily integration: research, theory, and best practices, 1 st ed. Elsevier Academic Press, Amsterdam

Kossek EE, Pichler S, Bodner T, Hammer LB (2011) Workplace social support and work-family conflict: a meta-analysis clarifying the influence of general and work-family-specific supervisor and organizational support. Pers Psychol 64(2):289-313

McElwain A, Korabik K, Chappell D (2004) Beyond gender: reexamining work-family conflict and work-family guilt in the context of gender-role orientation. Paper presented at the meeting of the International Society for the Study of Work and Organizational Values, New Orleans. ISSWOV, Budapest

McElwain A, Korabik K, Rosin HM (2005) An examination of gender differences in work-family conflict. Can J Behav Sci 37(4):269-284

Michel JS, Kotrba L, Mitchelson JK, Clark MA, Baltes BB (2011) Antecedents of work-family conflict: a meta-analytic review. J Organ Behav 32(5):689-725

Radloff LS (1977) The CES-D scale: a self report depression scale for research in the general population. Appl Psychol Meas 1:385-401

Rantanen J, Pulkkinen L, Kinnunen U (2005) The big five personality dimensions, work-family conflict, and psychological distress: a longitudinal view. J Individ Differ 26(3):155-166

Sekine M, Chandola T, Martikainen P, Marmot M, Kagamimori S (2006) Work and family characteristics as determinants of socioeconomic and sex inequalities in sleep: the Japanese Civil Servants Study. Sleep 29:206-216

Selvarajan T, Cloninger PA, Singh P (2013) Social support and workfamily conflict: a test of an indirect effects model. J Vocat Behav 83(3):486-499

Voydanoff P (2002) Linkages between the work-family interface and work, family and individual outcomes: an integrative model. J Fam Issues 23(1):138-164

Wang J (2005) Work stress as a risk factor for major depression. Psychol Med 35:865-871

Publisher's note Springer Nature remains neutral with regard to jurisdictional claims in published maps and institutional affiliations. 